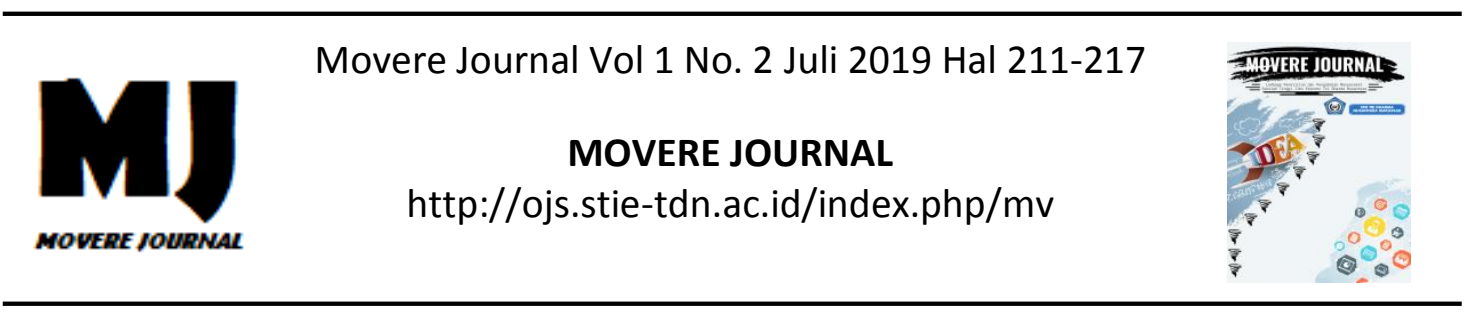

\title{
PENGARUH KOMPENSASI TERHADAP KEPUASAN KERJA KARYAWAN PADA PT. GRAHA SARANA DUTA MAKASSAR
}

\author{
Sulaeman $^{1)}$ Ady Andardinata ${ }^{2)}$ \\ STIE Tri Dharma Nusantara
}

\begin{abstract}
Abstrak : Pengaruh Kompensasi Terhadap Kepuasan Kerja Karyawan pada PT. Graha Sarana Duta Makassar.Penelitian ini bertujuan untuk menegetahui pengaruh kompensasi terhadap kepuasan kerja karyawan pada PT. Graha Sarana Duta Makassar. Adapun jenis data yang digunakan adalah data kualitatif dan data kuantitatif kemudian sumber vdata yang digunakan adalah data primer dan data sekunder dengan jumlah responden sebanyak 31 orang. Data - data tersebut diolah sedemikan rupa sehingga memberikan pemahaman yang sistematis. Selanjutnya diadakan perhitungan statistic dengan analisis regresi linear sederhana, koefisien korelasi (r), koefisien determinasi $\left(\mathrm{r}^{2}\right)$ dan uji t. Dari hasil perhitumgan diperoleh nilai regresinya sebesar $\mathrm{Y}=13,023+0,576 \mathrm{X}$. sedangkan nilai koefisien korelasinya $(\mathrm{r})$ sebesar 0,689 dan koefisien determinasinya $\left(\mathrm{r}^{2}\right)$ sebesar 0,47 atau $47 \%$. Hasil perhitungan uji $\mathrm{t}$ menunjukkan $\mathrm{t}_{\text {hitung }}>\mathrm{t}_{\text {tabel }}$ yaitu 5,124 >1,699. Hal ini menunjukkan bahwa terdapat pengaruh yang positif dan signifikan antara kompensasi terhadap kepuasan kerja karyawan pada PT. Graha Sarana Duta Makassar.
\end{abstract}

Keyword : Kompensasi, kepuasan kerja

\section{PENDAHULUAN}

Manajemen sumber daya manusia merupakan bagian dari manajemen keorganisasian yang menfokuskan diri pada unsure sumber daya manusia. Mengelola simber daya manusia secara baik dapat memberikan manfaat yang besar bagi organisasi. Dalam organisasi, sumber daya manusia maerupakan salah satu unsure yang terpenting, tanpa peran sumber daya manusia meskipun berbnagai factor yang dibutuhkan tersedia organisasi tidak akan berjalan karena sumber daya manusia merupakan penggerak dan penentu jalannya suatu organisasi.

Mengingat bahwa dalam kehidupan sehari hari manusia sebagai makhluk social, selalu melakukan kegiatan atau aktivitas baik secara bersama sama ataupun secara individual. Salah satu macam aktivitas manusia tersebut diwujudkan dalam suatu kegiatan yang disebut kerja. Aktivitas ini mengandung unsure kegiatan social, menghasilkan sesuatu yang pada akhirnya bertujuan untuk memenuhi kebutuhan hidupnya. Karyawan yang telah bekerja menyumbangkan tenaga dan fikirannya tersebut akan mendapatkan kompensasi yang sesuai tenaga yang dikeluarkan.

Pemberian Kompensasi secara adil dan layak kepada karyawan dapat berdamak positif bagi kemajuan dan keberhasilan suatu organisasi, karena karyawan akan bekerja secara maksimal dalam menyelesaikan setiap tugas yang diberikan oleh perusahaan 
terhadap karyawan. Tentunya kompensasi yang diterima oleh setiap karyawan berdampak pada kepuasan kerja karyawan secara positif dan signifikan sehingga secara tidak langsung semangat kerja yang diperlihatkan karyawan juga semakin baik, dengan semangat kerja yang baik tersebut diharapakan kinerja karyawan juga semakin baik dan tentunya produktivitas setiap karyawan juga mengalami peningkatan yang cukup positif.

Kepuasan kerja merupakan suatu perasaan yang berhubungan dengan pekerjaannya maupun dengan dengan kondisi dirinya. Perasaan yang berhubungan dengan pekerjaan melibatkan aspek aspek seperti upah atau gaji yang dietrima, kesempatan pengembangan karir,hubungan dengan karyawan lainnya, panutan kerja, jenis pekerjaan, struktur organisasi perusahaan dan mutu pengawasan. Sedangkan perasaan yang berhubungan dengan dirinya adalah umur, kondisi kesehatan, kemampuan atau skill serta pendidikan. Karyawan akan merasa puas dalam bekerja jika aspek-aspek pekerjaan tersebut bias diwujudkan oleh suatu organisasi atau perusahaan.

Tujuan penelitian ini adalah untuk mengetahui pengaruh kompensasi terhadap kepuasan kerja karyawan pada PT. Graha Sarana Duta Makassar.

\section{TELAAH LITERATUR DAN PENGEMBANGAN HIPOTESIS}

\footnotetext{
Manajemen Sumber Daya Manusia

Menurut Mangkunegara (2016:2)

'Manajemen sumber daya manusia merupakan suatu perencanaan, pengorganisasian, pelaksanaan dan pengawasan terhadap pengadaan, pengembangan, pemberian balas jasa, pengintegrasian, pemeliharaan, dan pemisahan tenaga kerja dalam rangka mencapai tujuan organisasi““.
}

Sedangkan menurut Rachmawati (2008:3) "Manajemen sumber daya manusia merupakan suatu proses perencanaan, pengorganisasian, pengarahan dan pengawasan kegiatankegiatan pengadaan, pengembangan, pemberian kompensasi, pemisahan tenaga kerja, pengintegrasian, pemeliharaan, balas jasa dan pelepasan sumber daya manusia agar tercapai berbagai tujuan individu, organisasi dan masyarakat yang sesuai dengan harapan yang ingin dicapai dalam suatu perusahaan". Selanjutnya Rivai (2011:1) "Manajemen sumber daya manusia merupakan salah satu bidang manajemen yang meliputi segi-segi perencanaan, pengorganisasian, pelaksanaan dan pengendalian. Karena sumber daya manusia dianggap semakin penting perannya dalam mencapai tujuan organisasi maka berbagai pengalaman dan hal peneliyian dalam bidang sumber daya manusia dikumpulkan secara sistematis".

Dari beberapa defenisi diatas dapat disimpulkan bahwa manajemen sumber daya manusia merupakan suatu aktivitas atau kegiatan dalam mengatur perencanaan, pengorganisasian, pelaksanaan dan pengawasan terhadap karyawan atau pegawai dalam pengembangan, pemberian kompensasi, pemeliharaan, pemutusan hubungan kerja agar lebih efektif dan efisien demi terwujudnya tujuan perusahaan, individu dan masyarakat.

\section{Kompensasi}

Menurut Notoatmodjo (2015:142) Kompensasi adalah segala sesuatu yang diterima oleh karyawan sebagai balas jasa untuk kerja atau pengabdian mereka. Sedangkan menurut Afifuddin (2014:181) Kompensasi adalah sebuah pendapatan yang berbentuk uang, barang langsung atau tidak langsung, yang di terima oleh karyawan sebagai 
imbalan balas jasa yang diberikan kepada perusahaan.

Selanjutnya Wibowo (2012:348) "Kompensasi merupakan kontra prestasi terhadap penggunaan tenaga kerja atau jasa yang telah diberikan oleh tenaga kerja. Kompensasi merupakan jumlah paket yang ditawarkan organisasi kepada pekerja sebagai imbalan atas penggunaan tenaga kerjanya.

Dari beberapa pengertian kompensasi diatas dapat disimpulkan bahwa kompensasi merupakan sejumlah balas jasa atau pendapatan yang diperoleh seorang karyawan dalam bentuk uang ataupun dalam bentuk barang, baik langsung ataupun tidak langsung yang diberikan oleh perusahan setelah menyelesaikan tugas atau pekerjaannya.

\section{Kepuasan Kerja}

Menurut Mangkunegara

(2016:117) Kepuasan kerja adalah perasaan menyokong atau tidak menyokong yang dialami karyawan dalam bekerja. Sedangkan meurut Sutrisno (2009:75) Kepuasan kerja adalah keadaan emosional yang menyenangkan atau tidak menyenangkan bagi karyawan memandang pekerjaan mereka.

Selanjutnya Robbins dalam Wibowo (2012:501) Mengatakan bahwa kepuasan kerja adalah sikap umum yang menunjukkan perbedaan antara jumlah penghargaan yang diterima pekerja dan jumlah yang mereka yakini seharusnya mereka terima. Dari beberapa defenisi kepuasan kerja yang dikemukakan para ahli, maka dapat disimpulkan bahwa kepuasan kerja merupakan perasaan secara emosional baik senang atau tidak senang yang ditunjukkan oleh karyawan terhadap pekerjaan yang diberikan perusahaan.

\section{Kerangka Pikir}

Kerangka pemikiran adalah suatu diagram yang menjelaskan secara garis besar alur logika berjalannya sebuah penelitian. Kerangka pemikiran dibuat berdasarkan pertanyaan penelitian dan mempresentasikan suatu himpunan dari beberapa konsep serta hubungan diantara konsep-konsep penelitian tersebut.

\section{Hipotesis}

Adapun yang menjadi hipotesis dalam penelitian ini adalah diduga kompensasi berpengaruh psoitif dan signifikan terhadap kepuasan kerja karyawan pada PT. Graha Sarana Duta Makassar.

\section{METODE PENELITIAN}

\section{Pengumpulan Data}

Metode yang digunakan dalam pengumpulan adalah sebagai berikut:

a. Observasi, yaitu peneliti mengamati yang dikerjakan orang, mendengarkan yang mereka ucapkan, dan berpartisipasi dalam aktivitas orang lain untuk memperoleh informasi yang diinginkan.

b. Angket (Quesionery), yaitu Pengumpulan data yang dilakukan melalui daftar pertanyaan / pernyataan yang disiapkan untuk responden.

c. Wawancara, yaitu mendapatkan informasi dengan cara mengajukan pertanyaan langsung (Tanya jawab) kepada responden.

\section{Jenis dan Sumber Data}

a. Jenis data yang digunakan dalam penelitian ini adalah:

1) Data kualitatif, yaitu data yang diperoleh dari instansi dalam bentuk informas ibaik secara lisan maupun tulisan atau dengan kata lain yang sifatnya deskriktif.

2) Data kuantitaf, yaitu data yang diperoleh dari kantor berupa dalam bentuk angka laporan. 
b. Sumber data yang digunakan dalam penelitian ini adalah

1) Data primer adalah data yang diperoleh secara langsung dari sumber aslinya. Data primer ini diperoleh melalui hasil pengamatan dan melalui koesioner yang dibagikan.

2) Data Sekunder adalah data yang dikumpulkan secara tidak langsung dari sumbernya. Data sekunder ini diperoleh melalui dokumen yang ada dalam kantor serta berbagai literature bahan kuliah yang berkaitan dengan penelitian ini.

\section{Populasi dan Sampel}

a. Poulasi, Menurut Sugiyono (2017:80)"Poulasi adalah wilayah generalisasi yang terdiri atas objek atau subjek yang mempunyai kualitas dan karakteristik tertentu yang diterapkan oleh peneliti untuk dipelajari dan kemudian ditarik kesimpulannya". Poulasi dalam penelitian ini adalah seluruh karyawan pada PT. Graha Sarana Duta Makassar yang berjumlah 93 orang yang terdiri dari 31 karyawan tetap dan 62 karyawan kontrak.

b. Sampel, Sampel adalah bagian dari jumlah karakteristik yang dimilik oleh populasi tersebut.Maka sampel yang digunakan dalam penelitian ini adalah sampel jenuh. Adapun yang dijadikan sampel dalam penelitian ini adalah hanya karyawan tetap sebanyak 31 orang.

\section{Metode Analisis Data}

a. Metoda analisa yang digunakan dalam penelitian ini adalah analisis regresi linier sederhana untuk mengetahui pengaruh antara variabel $\mathrm{X}$ (Kompensasi) terhadap variabel $\mathrm{Y}$ (Kepuasan Kerja). Adapun rumus regresi linier sederhana adalah :

$$
\begin{aligned}
& \mathrm{Y}=\mathrm{a}+\mathrm{b}(\mathrm{x}) \\
& \text { Dimana }: \\
& \mathrm{Y}=\text { Kepuasan Kerja } \\
& \mathrm{X}=\text { Kompensasi } \\
& \mathrm{a}=\text { Konstanta } \\
& \mathrm{b}=\text { Koefisien Regresi }
\end{aligned}
$$

Untuk memperoleh nilai a dan $b$ dapat ditentukan dengan rumus sebagai berikut :

$$
\begin{aligned}
& b=\frac{n \sum x y-\left(\sum x\right)\left(\sum y\right)}{n \sum x^{2}-\left(\sum x\right)^{2}} \\
& a=\frac{\sum y}{n}-b \frac{\sum x}{n}
\end{aligned}
$$

b. Uji Korelasi (r) dan Determinasi $\left(r^{2}\right)$

Untuk menunjukkan besarnya keeratan hubungan antara kompensasi dengan kepuasan kerja digunakan rumus koefisien korelasi ( $\mathrm{r}$ )

$$
r=\frac{n \sum x y-\left(\sum x\right)\left(\sum y\right)}{\sqrt{\left\{n \sum x^{2}-\left(\sum x^{2}\right)\right\}} \cdot\left\{n \sum y^{2}-\left(\sum y^{2}\right)\right\}}
$$

Dimana $\mathrm{n}=$ responden

Untuk mengukur interval keeratan hubungan, digunakan standar pengukuran korelasi sebagai berikut :

Tabel 1 : Pedoman interprestasi koefisien korelasi ( r )

\begin{tabular}{|c|c|}
\hline Interval & Kriteria \\
\hline $0,00-0,19$ & Sangat Lemah \\
\hline $0,20-0,39$ & Lemah \\
\hline $0,40-0,59$ & Sedang \\
\hline $0,60-0.79$ & Kuat \\
\hline $0,80-1,00$ & Sangat Kuat \\
\hline
\end{tabular}

Sumber : Sugiono (2008: 184) 
Dalam analisis regresi agar koefisien korelasi yang diperoleh dapat diartikan maka dihitung indeks determinasinya, yaitu hasil kuadrat dari koefisien korelasi:

$$
r_{x y}^{2}=\left(r_{x y}\right)^{2}
$$

Indeks determinasi yang diperoleh tersebut digunakan untuk menjelaskan persentase variasi dalam variabel tidak bebas (Y) yang disebabkan oleh bervariasinya variabel bebas $(\mathrm{X})$.

\section{c. Uji t}

Untuk menguji hipotesis bahwa kompensasi berpengaruh terhadap kepuasan kerja dilakukan uji t, yaitu dengan membandingkan antara $t_{\text {hitung }}$ dengan $t_{\text {tabel }}$ pada $\alpha=0,05$.

Rumus yang di gunakan untuk menghitung $t_{\text {hitung }}$ adalah sebagai berikut :

$$
t=\sqrt{\frac{n-2}{1-r^{2}}}
$$

Adapun masing-masing kriteria pengujian hipotesis :

Apabila dari hasil perhitungan diketahui $t_{\text {hitung }}>t_{\text {tabel }}$ maka hipotesis nol $\left(\mathrm{H}_{0}\right)$ di tolak dan hipotesis alternatif $\left(\mathrm{H}_{\mathrm{a}}\right)$ di terima, hal ini berarti bahwa ada pengaruh positif atau signifikan antara kompensasi.

1) terhadap kepuasan kerja.

2) Sebaliknya apabila dari hasil perhitungan di ketahui $t_{\text {hitung }}<\mathrm{t}_{\text {tabel }}$ maka hipotesis nol $\left(\mathrm{H}_{0}\right)$ diterima dan hipotesis alternatif $\left(\mathrm{H}_{\mathrm{a}}\right)$ ditolak, iniberarti bahwa tidak ada pengaruh yang positif atau signifikan antara kompensasi dan kepuasan kerja.

Setelah itu, membandingkan nilai statistik $\mathrm{t}$ hitung dengan nilai statistik t tabel:

1) Apabila nilai statistik $t_{\text {hitung }}<$ nilai statistik $t_{\text {tabel}}$, maka Ho diterima

2) Apabila nilai statistik $t_{\text {hitung }}>$ nilai statistik tabel, maka Ho ditolak.

\section{HASIL PENELITIAN DAN PEMBAHASAN}

\section{Hubungan Kompensasi Terhadap Kepuasan Kerja Karyawan}

Untuk mengetahui pengaruh kompensasi terhadap kepuasan kerja karyawan, maka metode analisis yang digunakan adalah sebagai berikut :

a) Regresi Linear sederhana

Untuk mendapatkan persamaan regresi linear sederhana maka dalam perhitungan harus ditentukan terlebih dahulu komponen-komponen dan konstanta-konstanta a dan $b$ dengan menggunakan sampel sebanyak 31 orang.

Dari data hasil regresi tersebut, maka nilai $b$ dapat dihitung sebagai berikut:

$\mathrm{b}=\frac{n\left(\sum x y\right)-\left(\sum x\right)\left(\sum y\right)}{n\left(\sum x^{2}\right)-\left(\sum x\right)^{2}}$

$\mathrm{b}=\frac{31(59055)-(1464)(1247)}{31(69424)-(1464)^{2}}$

$\mathrm{b}=\frac{1830705-1825608}{2152144-2143296}$

$\mathrm{b}=\frac{5097}{8848}$

$b=0,576$

Untuk nilai a :

$\mathrm{a}=\frac{\sum y}{n}-\mathrm{b} \frac{\sum x}{n}$

$\mathrm{a}=\frac{1247}{31}-0,576 \frac{1464}{3731}$

$\mathrm{a}=40,225-27,202$

$a=13,023$

maka persamaan regresi linear sederhananya adalah :

$\mathrm{Y}=13,023+0,576 \mathrm{X}$ Interprestasi persamaan linear sederhana diatas adalah :

a. Koefisien regresi $(b)=0,576$ artinya apabila variabel 
kompensasi mengalami perubahan sebesar 1 (satu) satuan, maka diharapkan kepuasan kerja karyawan mengalami perubahan (meningkat) sebesar 0,576

b. Konstanta (a) = sebesar 13,023 artinya apabila variabel kompensasi sama dengan nol, maka kepuasan kerja karyawan sebesar 13,023.

2. Koefisien Korelasi $(r)$

Untuk mengetahui keeratan hubungan antara kompensasi dengan kepuasan kerja, maka digunakan analisis korelasi dengan perhitungan :

$$
\begin{aligned}
& r=\frac{n \sum x y-\left(\sum x\right)\left(\sum y\right)}{\sqrt{n} \sum x^{2}-\left(\sum x\right)^{2} n \sum y^{2}-\left(\sum y\right)^{2}} \\
& r \\
& =\frac{31(59055)-(1464)(1247)}{\sqrt{\left[31(69424)-(1464)^{2}\right]\left[31(50361)-(1247)^{2}\right]}} \\
& r \\
& =\frac{1830705-1825608}{\sqrt{[2152144-2143296][1561191-1555009]}} \\
& r=\frac{5097}{\sqrt{[81.372][67.350]}} \\
& r=\frac{5097}{7395,832} \\
& r=0,689
\end{aligned}
$$

Dari hasil perhitungan korelasi (r) diatas, dapat diketahui bahwa antara kompensasi dan kepuasan kerja berpengaruh dengan tingkat hubungan yang sedang.

\section{Koefisien Determinasi $\left(r^{2}\right)$}

Untuk mengetahui kemampuan kompensasi mempengaruhi kepuasan kerja, digunakan koefisien determinasi yaitu kuadrat dari koefisien korelasi dengan rumus sebagai berikut :

$$
r^{2}=r \times r
$$

Jadi nilai koefisien determinasi $\left(r^{2}\right)$ adalah sebagai berikut :

$r^{2}=0,689 \times 0,689$ $r^{2}=0,4747$ atau $47,47 \%$

Nilai tersebut menunjukkan naik turunnya kepuasan kerja sebesar $0,4747(47,47 \%)$ dipengaruhi oleh kompensasi, sedangkan sisanya sebesar 52,53\% dipengaruhi oleh faktor-faktor lain yang tidak diteliti,seperti motivasi, pelatihan,kepemimpinan dan lain lain 4. Uji statistik (Uji t)

Untuk membuktikan hipotesis sekaligus menguji signifikan ada atau tidaknya hubungan antara kedua variabel tersebut digunakan uji $t$ dengan rumus sebagai berikut :

$\mathrm{t}_{\text {Hitung }}=\mathrm{r} \sqrt{\frac{n-2}{1-r^{2}}}$

$\mathrm{t}_{\text {Hitung }}=0,689 \sqrt{\frac{31-2}{1-0,4747}}$

$\mathrm{t}_{\text {Hitung }}=0,689 \sqrt{\frac{3,710}{0,5253}}$

$\mathrm{t}_{\text {Hitung }}=5,124$

Berdasarkan hasil penelitian tersebut diperoleh nilai $t_{\text {hitung }}>t_{\text {tabel }}$ $(5,124>1,699)$ sehingga $\mathrm{H}_{\mathrm{o}}$ ditolak dan menerima $\mathrm{H}_{\mathrm{a}}$. Dengan demikian, hipotesis yang menyatakan bahwa kompensasi berpengaruh positif dan signifikan terhadap kepuasan kerja karyawan diterima. Hal ini didukung oleh teori yang dikemukakan oleh Malayu dalam Afifuddin (2014:197), yaitu kompensasi dilaksanakan oleh perusahaan untuk memberikan kepuasan dan mendorong karyawan dalam menjalankan tugas-tugasnya. Selanjutnya Edison, Emron dkk (2016:217)" kepuasan kerja bagi karyawan cenderung meningkatkan produktivitas, rasa bangga, dan komitmen tinggi pada pekerjaannya. Jika merujuk pada dimensi kepuasan, ada korelasinya dengan kepemimpinan, termasuk juga dengan kebijakan, kompensasi, kompetensi dan lingkungan". 


\section{KESIMPULAN}

Dari hasil pembahasan diatas menunjukkan bahwa nilai dari hasil analisis statistiknya diperoleh regresi linear sederhana sebesar $\mathrm{Y}=13,023+$ $0,576 X$, Nilai $\mathrm{r}$ sebesar $r=0,689$. Koefisien determinasinya sebesar $47,47 \%$ dan uji $t_{\text {hitung }}$ sebesar $5,124>t$ tabel. 1,699. Hal ini menunjukkan bahwa terdapat pengaruh yang positif dan signifikan antara kompensasi terhadap kepuasan kerja karyawan pada PT. Graha Sarana Duta Makassar.

\section{DAFTAR PUSTAKA}

Afifuddin.2014.Manajemen Personalia Bandung.CV Pustaka Bisnis

Edison. Emron, Anwar. 2016. Manajemen Sumber Daya Manusia. Bandung. Alfabeta.
Mangkunegara, AA, Anwar Prabu .2016. Manajemen Sumber Daya Manusia Perusahaan. Bandung. Remaja Rosdakarya

Notoatmodjo,Soekdjo.2015. Pengembangan Sumber Daya Manusia. Jakarta. Rieneka Cipta

Rachmawati, Kusdyah, Ike. 2008. Manajemen Sumber Daya Manusia. Yogyakarta. Andi.

Rivai, Veithzal, .2011. Manajemen Sumber Daya Manusia untuk Perusahaan. Jakarta. Rajawali Pers

Sugiyono. 2013. Metode Penelitian Administrasi, Edisi ke-14. Bandung. Alfabeta.

Sutrisno, Edy. 2009. Manajemen sumber Daya Manusia. Jakarta. Prenada media Group.

Wibowo, 2012. Manajemen Kinerja, Edisi Ketiga, Jakarta, Rajawali Pers 
ISSN 2656-2790 (online) 